\title{
Geomaterials and decay forms of the coastal towers of Piscinni and Foghe, Weastern Sardinia Gianfranco Carcangiu ${ }^{a}$, Paola Meloni ${ }^{b}$, Marcella Palomba ${ }^{a}$, Ombretta Cocco ${ }^{c}$, Fabio Sitzia $^{d}$, Arianna Murru ${ }^{\text {a, c }}$, Maura Carboni ${ }^{\mathrm{e}}$, Marta Casti ${ }^{\text {c, }}$ Alessandro Ruggieri ${ }^{\mathrm{b}}$ \\ ${ }^{a}$ Consiglio Nazionale delle Ricerche - Istituto di Scienze dell'Atmosfera e del Clima, Bologna, Italy, g.carcangiu@isac.cnr.it, m.palomba@isac.cnr.it, arianna.murru@unica.it, ${ }^{b}$ Università degli Studi di Cagliari, Dipartimento di Ingegneria Meccanica, Chimica e dei Materiali, Cagliari, Italy, paola.meloni@unica.it, ruggieri.alessandro@libero.it ${ }^{\mathrm{c}}$ Dipartimento di Ingegneria Civile, Ambientale e Architettura, University of Cagliari, Italy, ombretta.cocco@unica.it, arianna.murru@unica.it, marta.casti@unica.it, ${ }^{\mathrm{d}}$ Università degli Studi di Cagliari, Dipartimento di Scienze Chimiche e Geologiche, Cagliari, Italy, fasitzia@tiscali.it, ${ }^{\mathrm{e} U n i v e r s i t a ̀ ~ d e g l i ~ S t u d i ~ d i ~ S a s s a r i, ~}$ Dipartimento di Scienze Chimiche e Farmaceutiche, Sassari, Italy, maucarboni@uniss.it
}

\begin{abstract}
The distribution of Coastal Towers in Sardinia testify that foreign invasions, which occurred several times over the centuries, were particularly frequent and dangerous. The beginning of the eighth century signed an increase of the attacks from the sea. The most of Coastal Towers were built in the period of Spanish rule, from 1583 to 1720 . Despite numerous restorations over the years, many of these defensive structures are in critical conditions, some also affected by structural collapse. The building materials are closely related to local geological outcrops, and consist of sedimentary, magmatic and metamorphic rocks. Study of different lithotypes allowed assessing the vulnerability of different materials in different environmental conditions. Salts, transported by aerosols and deposited inside the porous structures, are the principal cause of decay of the building materials.

Chemical-physical and mineralogical-petrographic analyses, performed on some Towers allowed making some general assessments on their conservation status and restoration projects.
\end{abstract}

Keywords: Coastal towers, decay, geomaterials, Sardinia

\section{Introduction}

Six Coastal Towers, located along the coast of the provinces of Cagliari and Oristano, were investigated for conservation purposes of the materials in place. Several samples, collected from both different natural lithotypes and mortars forming the six artifacts of historical interest (Torre di Piscinni - Torre di Cala d'Ostia - Torre di Capo Boi - Torre di Flumentorgiu Torre di Foghe, Torre del Pozzo), were studied by the application of several techniques and tests for a complete mineral-petrographic characterization.
In this paper we only report data on two Coastal Towers, among the best known in Sardinia. The towers were selected based on criteria related to the more or less homogeneity of rock-types composition, forming the ashlars, as well as bedding mortars. This also for making a comparison among different forms of decay, due not only to different rock types, but also different environmental conditions.

Information about geological setting of the areas of edification and probable provenance quarries, are reported. 
As concerns the mortar in place, whose characterization is very important in restoration plan, several types were collected from the towers, and information about the their construction events was also acquired.

The results of the research are scheduled, and organized according to the following scheme:

1. brief description of the site and construction techniques;

2. geological framework and building materials;

3. sampling of materials;

4. results of the investigation in optical microscopy;

5. mineral characterization of the samples by the application of the X-Ray Powder Diffraction (XRPD) technique.

\section{Materials and Methods}

Qualitative mineral and mineral-petrographic studies were performed using polarizing microscope and XRPD technique, on both rocktypes and mortars.

Mineral-petrographic studies of several samples, collected from different types of mortars, were carried out by optical microscopy, in polarized light. Optical studies provided information about nature of binders and aggregates. The comparative analysis, performed by acquiring digital images, also favored the assessment of the aggregate-binder ratio.

Qualitative X-Ray Powder Diffraction (XRPD) data were collected by a Rigaku Geigerflex apparatus, using $\mathrm{CuK} \alpha$ radiation, at $30 \mathrm{kV}$ and $30 \mathrm{~mA}$, Ni filter, step sampling $0.02{ }^{\circ} 2 \theta$. Mineral identification was carried out by searchmatch software, using the JCPDS Database (1995) [1]. Each XRPD analysis of mortars was carried out on the bulk sample (binder+aggregate), so allowing to better evidence among the different features of the products. As concerns natural stones, the most representative rock types were characterized.

The scheme of sampling is reported for each Tower, in the respective paragraph.

\section{Results and discussion}

\subsection{Torre di Piscinni}

The tower is built on a promontory located approximately $3 \mathrm{~km}$ south of Cape Malfatano on the road leading to the port of Teulada. It is inaccessible by road, but a path guarantees access.

The tower is truncated-cone shaped, topped by battlements and embrasures. The diameter of the base is $10 \mathrm{~m}$, and the height of $9 \mathrm{~m}$. The accommodation, located about at $4 \mathrm{~m}$ from the ground, is a single circular small-sized room (d $=5.5 \mathrm{~m}$ ), closed by a dome vault supported by a central column. The openings are represented by a troniera, on the opposite side of the entrance, the fireplace, on the left, and the stairwell, on the right. On the parade gunboats, parapets and battlements are well preserved.

The entrance of the tower is oriented towards North.

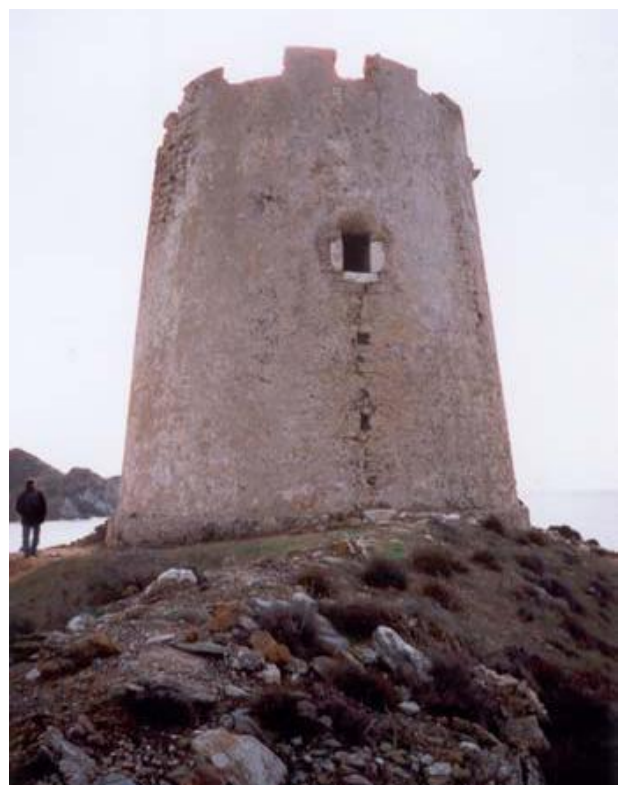

Fig. 1- Torre di Piscinni

Geological setting of the region is mainly represented by Middle Cambrian (Acadian) formations, consisting of sandstones and shales with trilobites. In the lower part, white, gray, or dark compact ceroid limestone, with 
Archaeocyatha, are interlayered with oolitic limestones [2].

The tower walls consist of sandstone blocks extracted from an ancient quarry, found in the underlying coast, which still preserves evident signs of the past mining works. Even shale was used as building stone, to level laying plans of sandstone ashlars.
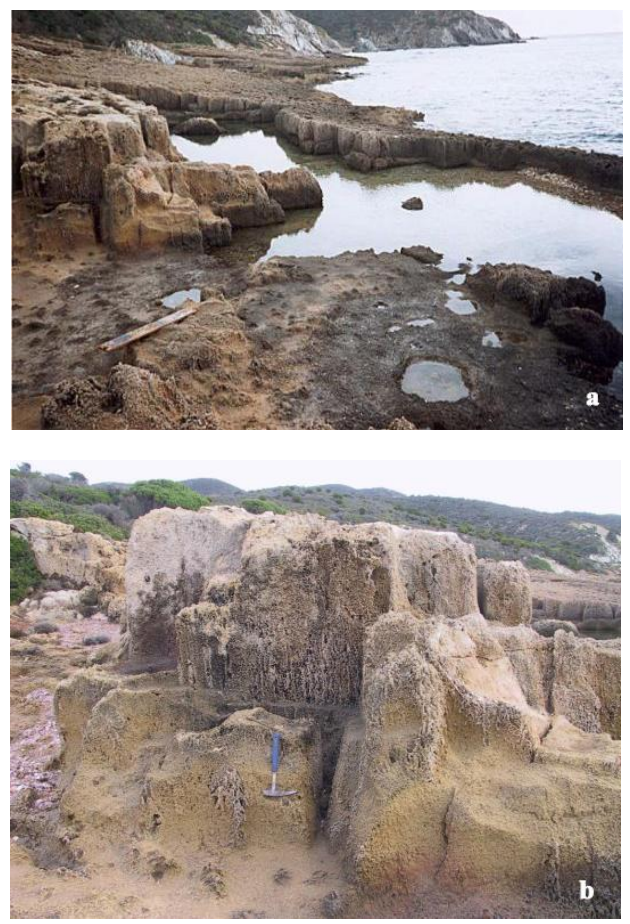

Fig. 2 a) and b) - The ancient quarry

The aggregate-binder ratios of lime mortars range from $1: 1$ to $4: 1$. Calcareous shells of lamellibranchia and foraminifera are recognizable inside the aggregate. The binder fraction shows abundant bio-alveolar structures and fossils (foraminifera and bivalves) principally inside the putty lime, where structures related to an original organogenic limestone still occur. The plaster is virtually absent in the surfaces facing the sea; in the protected side, towards the inland, tafones and flakings, partially restored in the past, frequently occur.

The dominant building lithotype is sandstone, characterized by the presence of macroscopic carbonatic/silicatic grains. Cement of the sandstone is carbonatic. Atmospheric agents easily attack sandstones. In particular, the dissolution phenomena of the carbonate cement, causing loss of cohesion among ashlars, frequently occur.

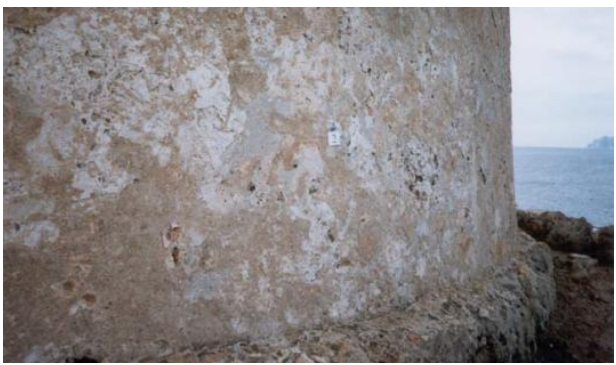

Fig. 3 - Northern side of the tower: wall covering partially restored

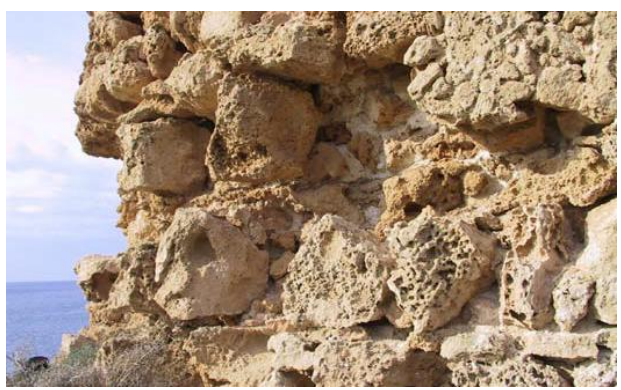

Fig. 4 - Inland side of the tower: evidences of tafones and flakings

The construction technique used involves the laying of superimposed stone elements layers, up to a thickness of about $50-60 \mathrm{~cm}$, and exclusively consisting of sandstone ashlars; shale was use between two sandstone layers, as a floor leveling.

The sampling of the mortars was carried out in 3 different points, according to the following scheme:

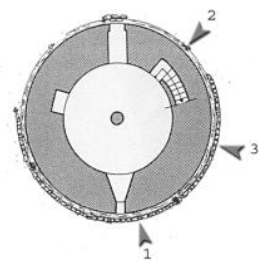

Fig. 5 - Sampling location 


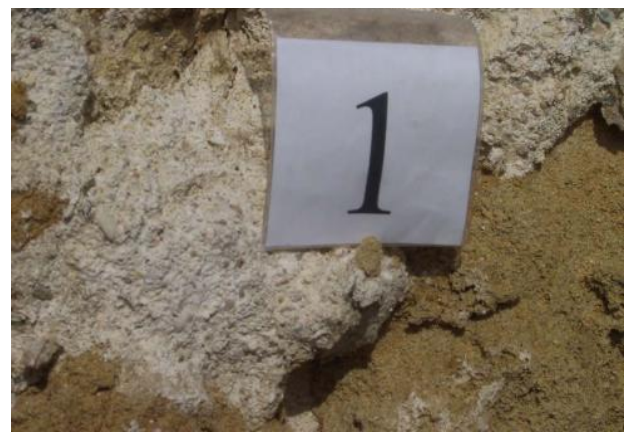

Fig. 6 - PSC-M1 sample - bedding mortar. The mortar is easy to breakage, whitish in color and full of shells inside.

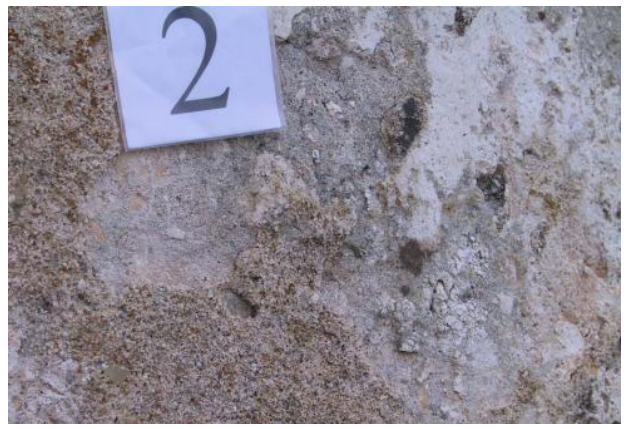

Fig. 7 - PSC-M2 sample - Plaster

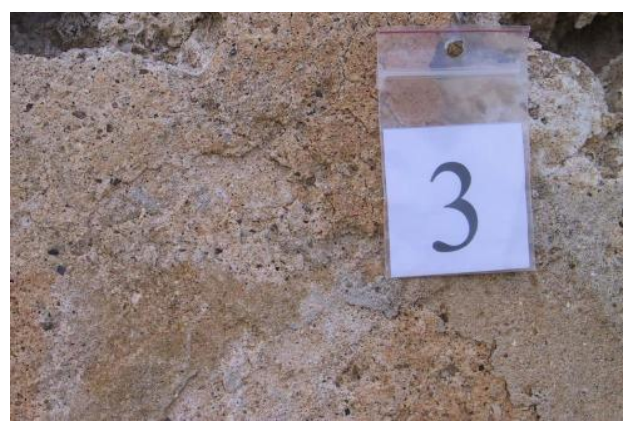

Fig. 8 - PSC-M3 sample - Plaster

\subsubsection{Mineral-petrographic studies}

\subsubsection{Mortars}

\section{Sample PSC-M1}

The mortar is made up of lime-based binder and quartz-feldspathic aggregate, with sub-rounded rock-fragments. Fossiles are mainly bivalves and gastropods. The aggregate-binder ratio is approximately $4: 1$.

\section{Sample PSC-M2}

The mortar, of poor quality, consists of putty lime as binder and carbonate aggregates with recognizable fossils (foraminifera and bivalves), deriving from an original organogenic limestone. Bio-alveolar structures can be recognized.

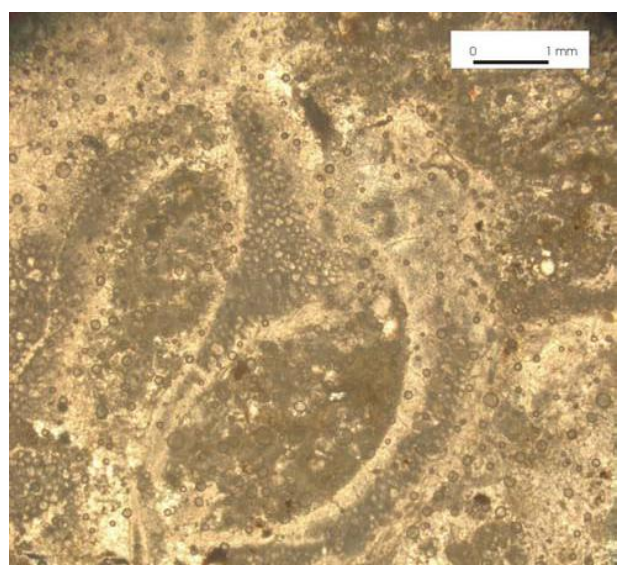

Fig. 9 - PSC-M2 sample - Plaster Microphotograph, parallel Nicols

Sample PSC-M3

A fossiliferous (gastropods) micritic carbonate matrix is recognizable. The silicatic aggregate, with grains of high-medium roundness, is monoand polycrystalline. The polymineralogic clasts consist of quartz and rock fragments in microgranular allotriomorphic structure; rare fragments of shells of lamellibranchia somewhere occur, along with fragments of metapelites featured by marked schistose texture. The aggregate-binder ratio is approximately $1: 1$.

Mineral composition of the mortars, by XRPD data, is composed by several mineral species. Sample PSC-M1 mainly consists of calcite, quartz and halite; plagioclases, K-feldspars and hematite occur as minor phases. Sample PSCM2 shows a similar composition, but without halite and hematite occurrences. Sample PSCM3 composition is different from the previous mortars, being simpler: only calcite and quartz are detectable. 

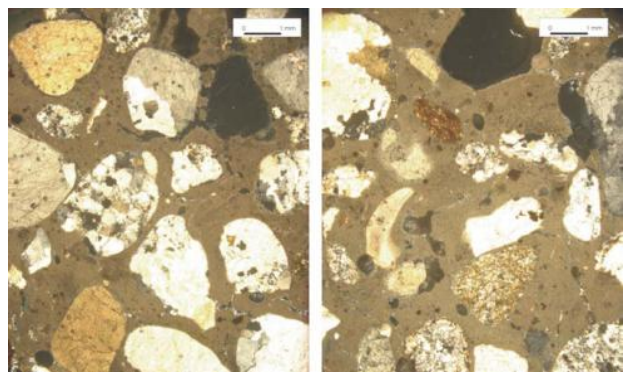

Fig. 10 - PSC-M3 sample - Plaster Microphotograph, parallel Nicols

\subsubsection{Rock-types}

Several samples of ashlars were collected from the tower and analyzed to investigate mineralpetrographic characteristics.

Optical studies evidence micro-fragments of different nature (including micro-fossils) inside a carbonate cement.

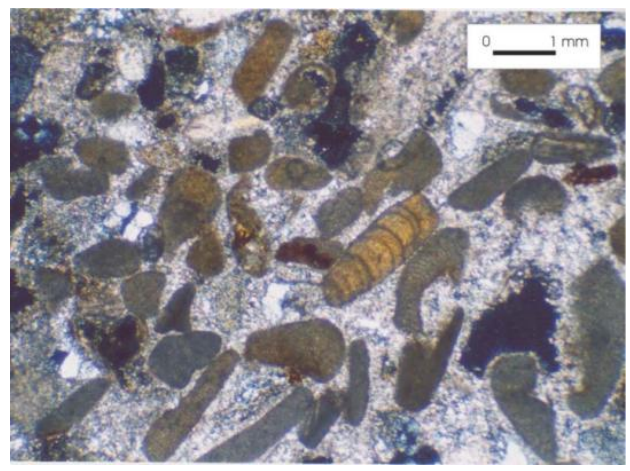

Fig. 11 - Microphotographs of sandstone sample, crossed nicols

Mineral composition of the sandstone ashlars, by XRPD data, consists of major calcite and quartz; plagioclases and illite/muscovite occur as minor phases; traces of chlorites locally occur.

\subsection{Torre di Foghe}

Located in the picturesque promontory of Punta Foghe, the tower is reachable from Tresnuraghes through an off-road route of about $11 \mathrm{Km}$.

The shape of the tower is like-cylindrical, and its small size, $8.60 \mathrm{~m}$ in diameter and $9.60 \mathrm{~m}$ in high, confirms the function of watchtower.

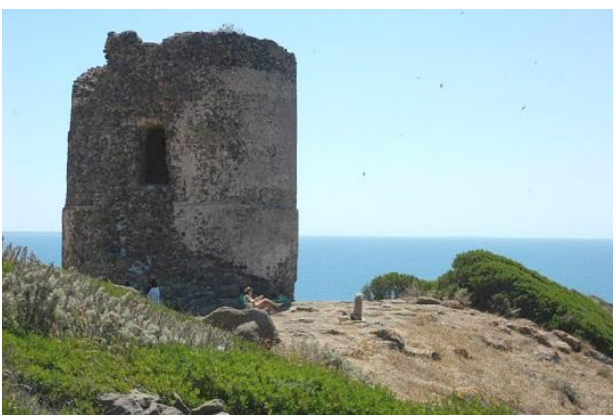

Fig. 12 -Torre di Foghe

The room, located about at $4 \mathrm{~m}$ above the ground, is covered by a dome vault (Fig. 13). In the room, a fireplace and a staircase, for the access to the terrace, are present.

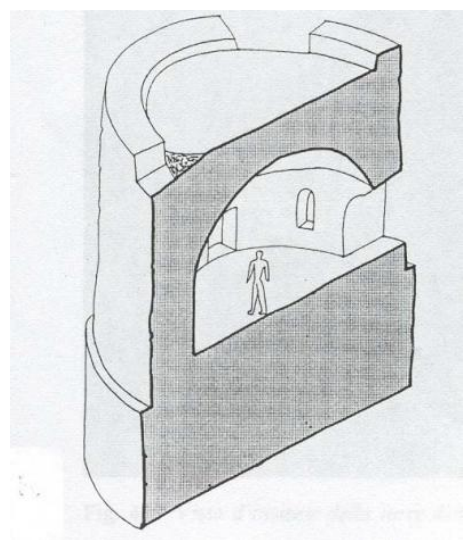

Fig. 13 -Torre di Foghe, isometric cross-section

Geological setting of the region consists of massive/layered glassy rhyolitic ignimbrites, locally kaolinized, belonging to the volcanic Oligocene-Miocene calc-alkaline cycle [3]. Pliocenic-Quaternary basalts, weakly alkaline and locally including phenocrysts, cover the Oligocene-Miocene volcanics. Coastal fossiliferous sandstones (Tyrrhenian bench) are recognizable along the coast, locally superimposed from the aeolian würmiane sandstones [4]. Towards E of Punta Foghe, Miocene formations, consisting of sandstones, calcareous and fossiliferous marl sandstones, overlay the more ancient formations [5].

Building materials forming Torre di Foghe strongly differ from those of the previous tower, 
mainly as concerns the lithotypes forming ashlars.

Ashlars mainly consist of basalt, rock resistant to the action of weathering agents; rhyolitic and sandstone ashlars locally occur, especially in the vaulted room. Ashlars forming the structure are not affected by significant alteration phenomena, except the presence of locally micro-tafones, generally affecting the surface of the tower exposed towards NW.

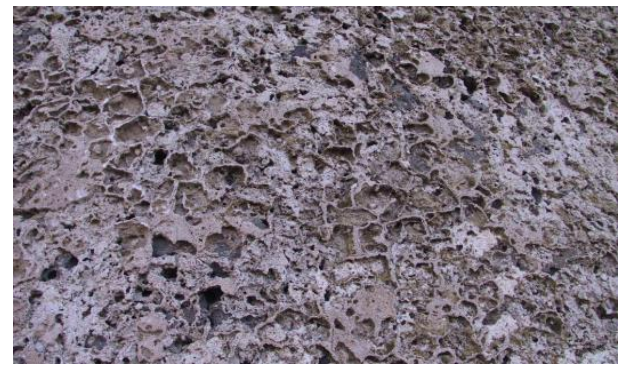

Fig. 14 - Torre di Foghe, tafones like- honeycomb in the exposed NO surface of the tower

Therefore, the decay of structure is mainly due to the removal of plaster and bedding resulting in detachment of the blocks. These damages are particularly evident at the base, and severely compromise the statics of the tower.

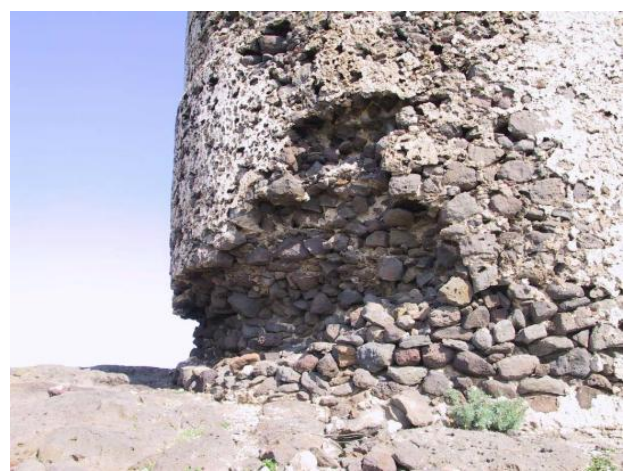

Fig. 15 - Torre di Foghe, erosion at the base

The mortars consist of a mixture of lime and sand aggregates including volcanic and carbonatic fragments, as well as shells of bivalves and gastropods.

Rare patches of plaster still occurring, are in a severe state of decay because affected by alveolization, tafones and spalling.
Twelve samples were collected from mortars, according to the following scheme:

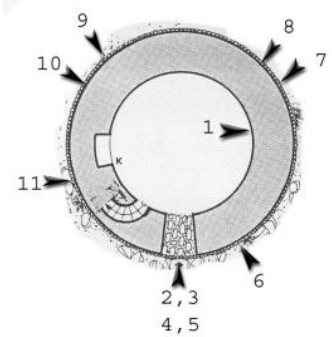

Fig. 16 - Sampling location of mortars

Samples from 1 to 5 , more samples 8,10 and 12 were collected from bedding mortars, samples 67-9 from plaster, sample 11 from the external finish coating.

In addition, two samples of building stones were collected. A sandstone sample was collected from the vault inside the tower, and a representative dark basalt sample from the masonry.

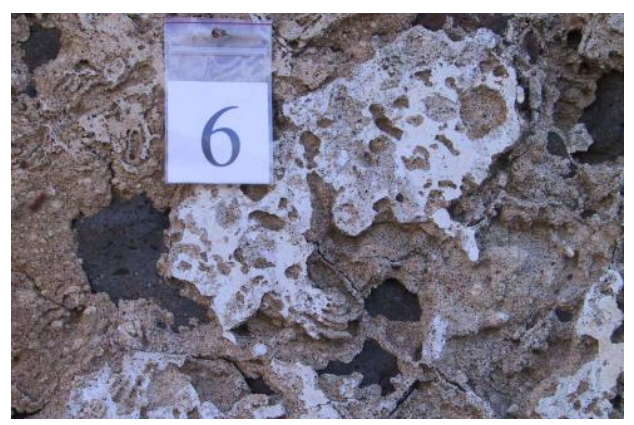

Fig. 17 - FOG-M6 sample - Plaster

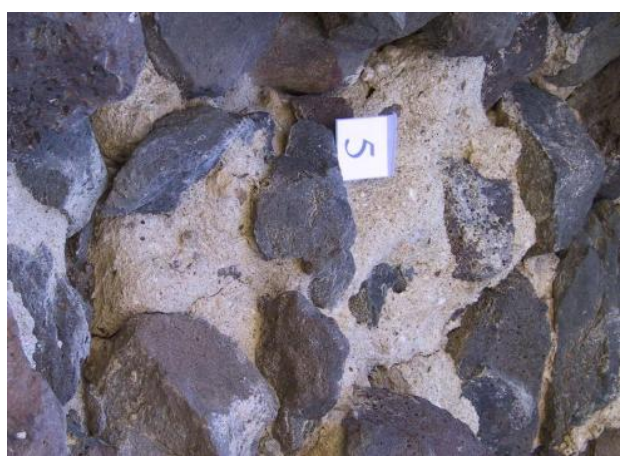

Fig. 18 - FOG-M5 sample - Bedding mortar 


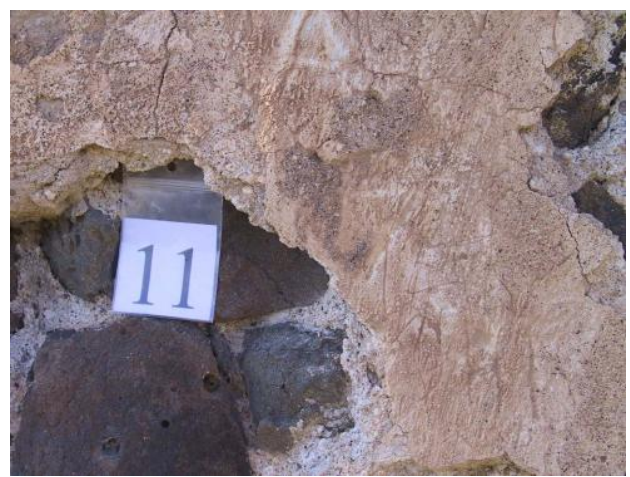

Fig. 19 - FOG-M11 sample - external finish coating

\subsubsection{Mineral-petrographic studies}

\subsubsection{Mortars}

Samples FOG-M1, M2, M3, M4, M5, M8, M10, M12

Optical studies show that bedding mortars have textural features quite similar. The aggregate/binder ratio is $1: 1$. The aggregates generally consist of abundant volcanic elements, subordinate quartz, plagioclase and K-feldspar. Fossils of bivalves and micritic limestone fragments are easily recognized. The elements of the aggregate are predominantly sub-rounded and minor sub-angular.

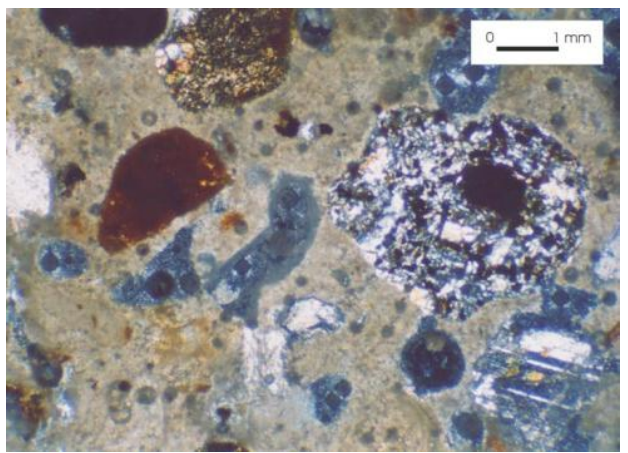

Fig. 20 - FOG-M5 Microphotograph, crossed nicols

\section{Samples FOG-M6, M7, M9}

Plasters have aggregate-binder ratio 1:1. Quartzfeldspathic aggregates include from sub-angular to sub-rounded elements. Plagioclases are abundant; in thin section they frequently show a typical oscillatory zoning. Phyllosilicates, mainly biotite, as well as micritic limestone and sandstone clasts, and fragment of fossils, can occur in some sample.

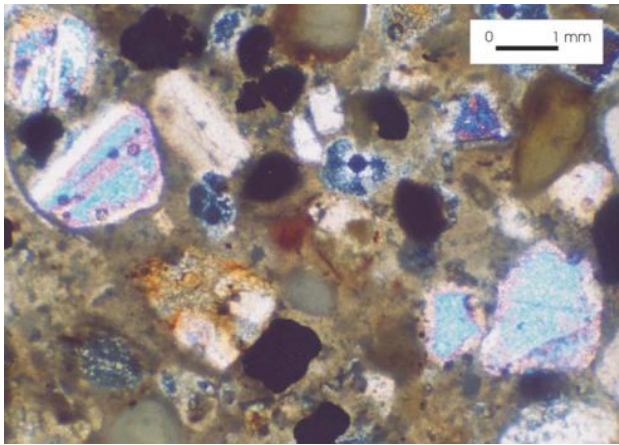

Fig. 21 - FOG-M7 Microphotograph, crossed nicols

\section{Samples FOG-M11}

Finish coating have an aggregate/binder ratio 1:1. The aggregate consists of quartz, plagioclase, K-feldspar sub-angular elements. The clastic fraction is abundant and mainly given by volcanic fragments and minor quartz. Fossils are seldom recognized.

Mineral composition of the bedding mortars, by XRPD data, is homogeneous and mainly consists of calcite, quartz, plagioclase, Kfeldspars. Minor halite occurs in sample FOGM10, while FOG-M2 is mono-mineralogic sample (calcite).

Plasters are mainly formed by calcite, quartz, plagioclases, K-feldspars; sample FOG-M7 also includes minor amount of halite.

Finally, the sample of finish coating mainly consists of the same mineral association of the previous mortar-types, like as calcite, quartz, plagioclases, and K-feldspars

\subsubsection{Rock-types}

XRPD data show a mineral composition of the sandstone samples given by calcite, quartz, plagioclases; plagioclase and pyroxene are the most common mineralogical phases of basalt samples. 


\section{Conclusions}

The analysis of the conservation status of these towers, chosen for their different structure of the wall outside, highlights the crucial role played by the coating and jointing mortars on stability and durability.

Although the mineralogical investigations have identified certain differences in the composition among constituents of the different mortars, is their presence and performance to ensure the proper degree of cohesion of the wall. The lack of the plaster to protect the structure and the usual choice in the design of the restoration, which has not provided, in these cases, its restoration, constitute points of weakness to the effects of the durability of the artifacts.
In this context it is emphasized, therefore, the need to operate with extreme skill and caution in selecting the correct mix-design of the repair mortar, as regards the binder and, to a same extent, the nature and the particle size distribution of the aggregates. Due to the poor mechanical performance of the original mortars, made with lime and local aggregates, the presence of the coating mortar would provided protection against the strong aggression of the coastal environment. These operational choices thus have repercussions on the programming of maintenance that, if not implemented, encourages decay phoenomena to be developed and accelerated.

\section{References}

JCPDS File (1995), Inorganic Phases. JCPDS International Centre for Diffraction Data, Swarthmore, U.S.A.

Carmignani L., Cocozza T., Ghezzo C., Pertusati P.C., Ricci C.A. (1982), Lineamenti del basamento sardo. Boll.Soc.Geol.It., Special Issue, Guida alla Geologia del Paleozoico Sardo, Guide Geologiche, pp. 11 - 23.

Marchi, M., Macciotta, G., Garau, A.M., (2002), Cainozoic magmatism in Sardinia and its geodynamic significance. Rend. Soc.' Paleont. It., 1, 343 - 348.

Ulzega A., Ozer A. (1982), - Comptes-Rendus de l'Excursion -Table rond sur le Tyrrhénien de la Sardaigne oriéntale. INQUA, Cagliari, p. 110.

Cherchi, A., Montadert, L., (1982), Oligo-Miocene rift of Sardinia and early history of the western Mediterranean Basin. Nature 298, pp. 736 - 739. 